\title{
A berlinda entre a democracia representativa e o controle social: os Conselhos de Representantes no governo do PT (2001-2004) na cidade de São Paulo
}

The hot seat between the representative democracy and social control: the Council of Representatives in the PT's governement (2001-2004) in São http://lattes.cnpq.br/9715457072186077 http://orcid.org/0000-0002-0488-8487 eduardo.grin@fgv.br

Resumo: $\mathrm{O}$ artigo analisa por que os Conselhos de Representantes, instâncias propostas pelo Partido dos Trabalhadores na campanha municipal em 2000 para ampliar o controle social sobre o governo local, não foram implementados. Teoricamente discute-se como novas instituições, quando consideradas promotoras de mudanças nas regras do jogo politico, tem dificuldade de serem implantadas, como ocorreu com os Conselhos. Avalia-se como os vereadores, visando manter seus interesses locais, travaram esse processo. O institucionalismo histórico será a base teórica: novos arranjos políticos e institucionais que alteram a distribuição prévia de poderes dos atores políticos tendem a gerar limitadas inovações de políticas. Este é um estudo qualitativo apoiado em fontes primárias (entrevistas) e secundárias (documentos oficiais e matérias jornalísticas). Concluiu-se que o governo priorizou construir sua coalizão de apoio no parlamento diante do temor da maioria dos vereadores que os Conselhos alterariam as práticas políticas institucionalizadas que lhes permitia ter influência política nos bairros.

Palavras chave: controle social; democracia participativa; descentralização; coalizão de governo; vereadores

\begin{abstract}
The article analyzes why the Council of Representatives, forum proposed by the Worker's Party in the municipal campaign in 2000 to expand the social control over the local government, weren't implemented. Theoretically we discuss how new institutions, when considered promoters of changes in the rules of the political game, have the difficulty of being implemented, as occurred with the Councils. We evaluate how the aldermen, seeking to keep their local interests curbed this process. The historical institutionalism will be the theoretical base: new institutional and political arrangements which change the previous distribution of power from political actors tend to generate limited policy innovation. This is a qualitative study based on primary sources (interviews) and secondary ones (official documents and news articles). We conclude that the government prioritized to build its coalition of support in the parliament before the fear of the majority of aldermen that the Councils would change the institutionalized political practices which permitted to them to keep political influence in the neighborhoods.
\end{abstract}

Key words: social control; participatory democracy; decentralization; government coalition; aldermen
Resumen: El artículo analiza por qué los Consejos de Representantes, instancias propuestas por el Partido de los Trabajadores en la campaña electoral del año 2000 para agrandar el control social sobre el gobierno local, no fueron implementadas. Teóricamente es discutido como nuevas instituciones, cuando consideradas como promotora de cambios en las reglas del juego político, presentan dificultades para se implantadas, como ocurrió con los Consejos. Es evaluado como los concejales, buscando mantener sus intereses locales, bloquearon ese proceso. El institucionalismo histórico es la base teórica: nuevos arreglos políticos y institucionales que cambian la distribución previa de poderes de los actores políticos tienden a generar limitadas innovaciones políticas. Este es un estudio cualitativo apoyado en fuentes primarias (encuestas) y secundarias (documentos oficiales y materias periodísticas). Se concluyó que el gobierno concedió prioridad para construir su coalición de apoyo en el parlamento delante de temor de la mayoría de los concejales que los Consejos cambiarían las prácticas políticas institucionalizadas que les posibilitaba tener influencia política en los barrios.

Palabras clave: control social; democracia participativa; descentralización; coalición de gobierno; concejales

Texto completo em português: http://www.apgs.ufv.br Full text in Portuguese: http://www.apgs.ufv.br

\section{Introdução}

Nem sempre propostas de controle social na administração pública podem ser virtuosas; pelo contrário, podem servir para alimentar práticas políticas tradicionais, pois, conforme Maquiavel, um vício pode ser uma virtude se o objetivo é manter o poder. Portanto, não chega a ser um paradoxo que propostas com essa finalidade acabem servindo para legitimar os interesses de atores políticos que se opõem a essas práticas. Esta foi a situação que envolveu a criação do Conselho de Representantes na cidade de São Paulo no governo petista da prefeita Marta Suplicy (20012004). Desde a década de 1950, a gestão dos territórios da cidade convive com distintas formas de organização política e administrativa. Entretanto, se a regionalização ampliou a presença do poder público, também serviu como recurso político para alimentar a construção de política de alianças na Câmara Municipal, pois nos bairros costuma-se localizar as clientelas eleitorais dos vereadores.

Este artigo, portanto, discute como a gestão Marta Suplicy recuou de implantar o Conselho de Representantes, doravante Conselhos. Estes fóruns seriam formados pela eleição direta de cidadãos para exercer controle social sobre as Subprefeituras nos bairros. Vale lembrar que o Partido dos Trabalhadores (PT) sempre 
foi um histórico defensor de instrumentos de democracia participativa. Na eleição municipal de 2000, o PT propôs os Conselhos como solução para reduzir a influência dos vereadores na administração pública regional. A democracia participativa seria uma solução para os limites da democracia representativa. Diante disso, este artigo analisa como e por que o PT abandonou essa proposta em favor do que esse mesmo partido chamava da política tradicional de partilha de poder com os vereadores nos bairros.

Vale ressaltar que o artigo não analisará os Conselhos, mas sim como a trajetória da proposta foi abandonada à medida que a construção de uma maioria parlamentar se impôs como prioridade política do governo. Dessa forma, este não é um texto para analisar experiências locais de democracia participativa, uma vez que o foco é compreender o que motivou as mudanças na ação política do PT. A literatura sobre esse tema nas cidades brasileiras não serve para responder por qual razão o PT não defendeu o alargamento da democracia participativa na cidade de São Paulo na gestão Marta Suplicy.

A referência ao Conselho serve de contraste à democracia representativa nos termos de Dahl (2005) e Manin (1995). Quanto à democracia participativa, trata-se de combinar a ação política mais direta da sociedade com instituições representativas, mas não de substituí-las (Castells, 1989). Por exemplo, seria possível e razoável projetar um sistema onde associações comunitárias pudessem controlar e supervisionar os vereadores? Foi uma variante desta, proposta de Castells (1989), que inspirou os Conselhos na cidade de São Paulo.

Mas o que pode ocorrer com propostas como essas se elas são vistas como perigosas pelos protagonistas locais de democracia representativa - os vereadores? Implementar arranjos deste tipo aumentaria sua relevância no governo municipal e reduziria o poder dos vereadores? O artigo trata dessa questão, enfocando a disputa que envolveu o projeto para ampliar a democracia representativa com a participação mais direta da sociedade e os vereadores interessados em manter suas "pequenas soberanias" (Dahl, 1989) nos bairros.

Teoricamente, discute-se como novas instituições, quando são vistas como promotoras de mudanças nas regras do jogo da política municipal, tem uma grande probabilidade de serem derrotadas. Se os atores políticos que se favorecem compreenderem que as inovações políticas podem obstruir seus objetivos, por qual motivo então apoiar mudanças nas regras de um jogo cuja institucionalização atende aos seus interesses?

Para analisar essa questão, o neoinstitucionalismo histórico será a base do argumento teórico: mudanças em arranjos políticos e institucionais que alteram a distribuição prévia de poderes dos atores políticos tende a transformar-se em uma inovação limitada de políticas. Empiricamente, a hipótese é que a trajetória da política municipal em São Paulo sempre foi constrangida pela ação dos vereadores, visando manter seus interesses nos bairros.

Esse traço da política municipal evidenciou-se quando foi proposta a inovação institucional dos Conselhos, pois os vereadores consideravam que esse prejudicariam seus interesses. Como o governo do PT priorizou construir sua coalizão de apoio na
Câmara Municipal, as regras historicamente institucionalizadas da política municipal acabaram por limitar o alargamento da democracia participativa.

O artigo está organizado como segue. Inicia-se apresentando os procedimentos metodológicos; em segundo lugar, revisam-se alguns argumentos do institucionalismo histórico, sobretudo o conceito de "inovação limitada" (Weir, 1992). A terceira seção apresenta a concepção política do PT sobre os Conselhos; a quarta parte aborda o debate entre o governo e a Câmara Municipal, que gerou os impasses e escolhas envolvendo a inovação institucional e a política tradicional. Segue-se analisando como e por que foi desconstruída a proposta dos Conselhos. Na conclusão, avalia-se as questões que limitavam as mudanças na política municipal, conforme concebidas pelo PT para fortalecer a democracia participativa diante das instituições da democracia representativa.

\section{Procedimentos metodológicos}

Este é um estudo de caso historicamente orientado, pois busca investigar configurações e causas contextuais, já que tal recurso possibilita apreender a conjuntura onde ocorre a ação humana em assuntos de natureza social e política (Ragin, 1987). Para Ragin (1987, p. 3), os casos são configurações que visam "explicar resultados históricos específicos, a totalidade de resultados comparáveis ou o processo escolhido a ser estudado por causa de seu significado para os arranjos institucionais ou para a vida social em geral". É possível encontrar condições causais convergentes que inserem uma análise individual em uma configuração mais ampla. Estudos de caso permitem reunir evidências sensíveis à cronologia dos fatos para entender o caminho de eventos significativos e associações entre causas e efeitos, desde que orientado por categorias teóricas (Gerring, 2007).

Em estudos de caso, o ponto inicial é especificar em quais unidades o exame do pesquisador está focalizado, com o cuidado de evitar análises particularistas que não permitem verificar a validação de pressupostos teóricos. Igualmente, é difícil avaliar o impacto dos casos sem analisar os atores políticos e seus credos em "circunstâncias estruturais" históricas. A generalização analítica inicia em unidades sociais específicas, sobretudo dos atores políticos agindo neste contexto, sempre com relação a "se" alguns fatores estão presentes para gerar conclusões mais amplas. Estudos de caso produzem análises "historicamente genuínas" e assumem o tempo e o lugar em que uma estrutura ou processo faz a diferença. Portanto, a sequência de eventos impacta os resultados contextuais e exige uma investigação sistemática em vez de sínteses imediatas e pouco informadas (Tilly, 1983).

Considerando essas premissas metodológicas, realizaram-se cinco entrevistas utilizando-se um roteiro semiestruturado questões (ver anexo). O período de sua realização foi entre fevereiro e agosto de 2010 (quatro na Capela do Socorro - região sul - e três na Freguesia do Ó - região norte). Nas 31 Subprefeituras, essas regiões representaram duas maneiras opostas de compartilhar o poder com os vereadores, conforme Gerring (2007, p. 99) concebe essa opção como um método de casos diversos para analisar o mesmo objeto. A "diversidade pode referir-se a uma gama de 
variação em X1 ou $\mathrm{Y}$, ou a uma combinação particular de fatores causais (com ou sem uma consideração do resultado). Em cada situação, a seleção de caso visa capturar a variação ao longo da (s) dimensão (s) de interesse" (idem, ibid).

A Capela do Socorro manteve a hegemonia do PT em todo o governo no período de 2001 a 2004. Na Freguesia do Ó, o PT cedeu a liderança política a um adversário político de um partido "tradicional" e conservador chamado Partido Liberal (PL). Trata-se de duas regiões com trajetórias políticas diferentes e duas distintas variáveis dependentes para a mesma condição causal, que foi a criação das Subprefeituras: na Capela do Socorro não houve nenhuma mudança na hegemonia política, enquanto na Freguesia do Ó a Subprefeita do PT foi substituída por um antigo adversário político. Foram entrevistados os Subprefeitos à frente das duas regiões na gestão Marta Suplicy (Capela do Socorro de 2001 a 2004 e na Freguesia do Ó de 2003 a 2004 quando assumiu o indicado por um vereador do PL.No governo "central" foram entrevistados três atores chave que atuaram na administração Marta Suplicy no período 2001-2004, considerando sua influência sobre a proposta dos Conselhos: Chefe de Gabinete da Secretaria de Governo (responsável pela relação com os vereadores), Coordenador Municipal do Orçamento Participativo (responsável pelo tema da participação popular) e a Secretária Municipal de Assistência Social (ex-Secretária de Administração Regional no primeiro mandato do PT em São Paulo (1989-1992).

As entrevistas foram agendadas com base na técnica "bola de neve" ao solicitar indicações dos entrevistados de atores políticos que poderiam contribuir com a pesquisa. Quanto aos critérios para selecionar os entrevistados, diante da questão de interesse central da pesquisa, priorizaram-se Subprefeitos e coordenadores setoriais. A razão básica é que esses eram os dirigentes políticos e gerenciais conhecedores do processo político envolvido nas Subprefeituras no governo Marta Suplicy (2001-2004), o que, por sua vez, impactou na forma como foi conduzido o processo de implantação dos Conselhos ${ }^{1}$ Ademais, analisaram-se documentos (leis, pareces e projetos substitutivos) referenciados ao final do texto em "Outras fontes". Por fim, temos o estudo hemerotécnico dos jornais (Folha de São Paulo e Estado de São Paulo) que, de 2001 a 2004, descreveram a evolução desse debate na Câmara Municipal.

As informações obtidas por meio das entrevistas foram analisadas cotejando-as com o marco teórico utilizado. Como não se tratava de uma análise de conteúdo em sentido estrito desse corpus, conforme a concepção clássica de Bardin, mas sim de conhecer opiniões sobre o processo político relacionado à implantação dos Conselhos, tal abordagem é suficiente para os fins da discussão realizada. Quanto à análise documental, utilizaram-se dois procedimentos básicos: a) um descritivo localizando as Subprefeituras e os Conselhos na legislação municipal para evidenciar que havia suporte jurídico para sua implantação; b) um

${ }^{1}$ A listagem dos entrevistados e dos respectivos bairros em que atuaram na gestão Marta Suplicy (2001-2004) encontra-se no final do artigo. Ao longo do analítico, em linha com as categorias teóricas discutidas na próxima seção.

\section{O processo político e as limitações institucionais para sua mudança}

Para Weir (1992), a inovação limitada em políticas refere-se a arranjos institucionais que criam oportunidades de mudança, mas também sofrem constrangimentos para tal. Com o passar do tempo, algumas ideias tornam-se menos prováveis de influenciar as políticas das instituições e reduzem os incentivos para as escolhas dos atores políticos sobre manter ou alterar o status quo. O lócus institucional pode afetar a capacidade de os grupos influenciarem as políticas, e a forma como seus interesses são definidos leva-os a construir coalizões políticas (Lowi, 1964). Portanto, é importante entender como os grupos inserem seus interesses nas políticas e como esse processo pode criar conflitos nas instituições.

Conforme Weir (1992), as políticas e instituições moldam as possibilidades de ação dos atores e a forma como inovações propostas são consideradas. Por exemplo, a organização interna do Estado pode influenciar o desenho de políticas, bem como mudanças institucionais podem afetar os interesses dos atores políticos. Para Weir (1992, p. 192):

Inerente nessa abordagem está a noção que inovações individuais são parte de uma "sequência de políticas" nas quais o desenvolvimento institucional apresenta algumas interpretações de problemas mais persuasivos e faz algumas políticas mais viáveis que outras. Subjacente ao conceito de uma sequência de políticas está a noção de "dependência da trajetória": decisões em um ponto no tempo podem restringir futuras possibilidades de enviar as políticas para fora de caminhos particulares ao longo do qual as ideias, interesses, instituições e estratégias se adaptam.

O passado das políticas é um mecanismo explicativo para analisar como os atores políticos atuam, bem como pode explicar por que ações inovadoras enfrentam interesses dos atores em domínios de políticas (Hall, 1993). Tais confrontos são pontos de inflexão, mas também de contingência política, e criam oportunidades para novas abordagens dos atores políticos. Todavia, como as ideias sobre as inovações são traduzidas em linguagem apropriada para a decisão política, muitas vezes resultam em metamorfose das noções originais. Nesse particular, os partidos políticos e os seus representantes eleitos têm um papel crucial nesta "tradução" (King, 1992).

Um efeito desta "elucidação" é uma "inovação limitada" na política e nas políticas, pois não é incomum que ela coexista com características prévias da configuração institucional aceita pelos atores políticos. Sobretudo quando o governo tem interesse em manter certas regras, há "dificuldades em estender os limites institucionalmente enraizados da política existente" (Weir, 1992, p. 211). A construção de alianças políticas, para Weir (1992, p. 194), exemplifica essas limitações, pois:

Um dos mais poderosos fatores determinando como grupos definem seus interesses em políticas, e em quais alianças entram, é a organização das instituições políticas. Os aspectos do sistema

texto as entrevistas são identificadas por números para preservar a identidade dos fornecedores das informações. 
político que agregam interesses, em particular o sistema de partidos e a legislatura, são centrais. Por canalizarem o modo como os grupos interagem em políticas e produzem políticas, essas instituições afetam enormemente as possibilidades para diversos grupos reconhecerem interesses comuns, construir alianças políticas e frequentemente determinam se tais alianças são necessárias.

As reformas institucionais podem ser pré-requisitos para sedimentar novas iniciativas governamentais e exigem coalizões que devem ser analisadas para verificar por que alguns atores políticos são mais favorecidos do que outros. Novas instituições, em função da dependência da trajetória, restringem seu desenvolvimento diante de barreiras à inovação, mesmo que esse processo reposicione os atores políticos e seus interesses. A forma de gerir uma política pode criar problemas de tramitação no governo, especialmente se torna-se complexo obter consenso sobre as mudanças administrativas apoiadas em novas ideias, mas que enfrentam atores políticos que visam limitar o seu alcance (Weir, 1992).

Portanto, a forma como se estrutura uma política é chave para os atores políticos e seus interesses, pois pode gerar obstáculos para reorganizá-lo em novas bases. Por isso, importa conhecer o processo político subjacente às decisões governamentais. Instituições estabelecem o cenário para mediar conflitos e relações, e influenciam os resultados das políticas, pois moldam o contexto de incentivos, oportunidades e restrições. Os atores políticos formulam suas estratégias conforme os lugares ocupados no desenho institucional. Mas nas instituições mais de um curso de ação é possível porque essas não determinam os interesses dos atores (Immergut, 1992). Assim, mudanças no jogo político podem afetar o funcionamento institucional e gerar padrões díspares de comportamentos de atores políticos em uma mesma arena política.

Nesses termos, quando o partido vencedor expande os "direitos" de participação de alguns atores políticos ele pode alterar a divisão de poder e o cenário institucional. Mas essa partilha pode comprometer o curso de uma política se alguns atores forem menos considerados (Olsen, 1984; Thelen \& Steinmo, 1992). Este resultado decorre de "as políticas, uma vez adotadas, inserirem-se em instituições. Elas estão associadas a regras, expectativas e compromissos. Afetando os pensamentos e aspirações, eles afetam os comportamentos futuros dos participantes políticos" (Olsen, 1984, p. 745).

Cabe à análise institucional identificar as relações de poder e os arranjos institucionais inseridos nas políticas governamentais, pois ambos podem afetar a ação e os interesses dos atores políticos. Por exemplo, manobras de atores políticos podem influenciar os parâmetros institucionais em que atuam, bem como esses podem rever suas estratégias se seus interesses não são considerados. Assim, "onde grupos têm interesses múltiplos, muitas vezes conflitantes, é necessário examinar o processo político a partir do qual se formam coalizões particulares" (Thelen \& Steinmo, 1992, p. 9).

\section{A base política da descentralização e o papel do Conselho de Representantes}

As Subprefeituras eram tidas como vitais para superar as desigualdades territoriais, democratizar o poder público e qualificar a gestão municipal, por meio da participação popular e dos Conselhos. Conforme o discurso da Coligação Muda São Paulo (2000, p. 12):

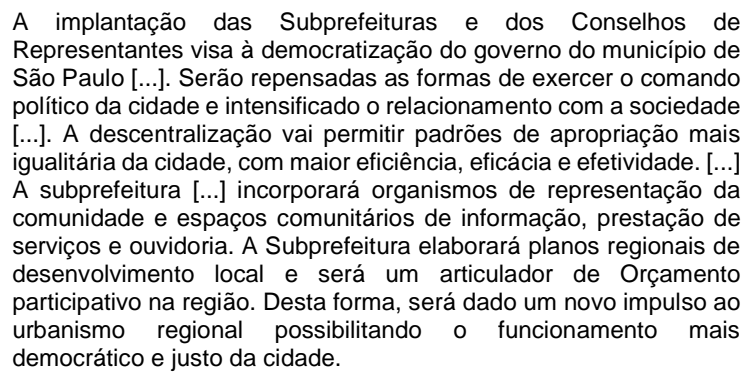
democrático e justo da cidade.

Como a centralização administrativa era pouco acessível à participação popular, a cidade seria repolitizada com a reforma da relação entre o governo e a sociedade (Santos e Barreta, 2004). As Subprefeituras democratizariam a gestão pública e criariam uma nova cultura política, pois mecanismos de controle social, como os Conselhos, reduziriam a influência e captura do poder local pelos vereadores (Sposati, 2002).

As políticas públicas seriam executadas de forma integrada, reorganizando a gestão das demandas locais em vez de centralizadas e setoriais (Martins, 2006, Fernandez \& Mendes, 2003). Com a descentralização e as políticas intersetoriais, as Subprefeituras qualificariam a prestação de serviços públicos. A coexistência organizacional dentro das Subprefeituras geraria mais proximidade entre todos os órgãos municipais que, no entanto, começariam a trabalhar de forma integrada, o que geraria maior racionalidade administrativa (Garibe, 2004, 2006, Donato, 2006 e Capucci, 2004). A descentralização, associada à democracia participativa, mudaria o poder público em favor da sociedade. As Subprefeituras implementariam esta política por estarem mais próximas do cidadão e seriam o caminho político e institucional para descentralizar a gestão das políticas públicas às regiões.

No entanto, para evitar que a gestão regional permanecesse presa à influência clientelista dos vereadores "tradicionais", o fórum de controle participativo e social seria a base da governança. $O$ diálogo direto com a população reduziria a intermediação de interesses locais apenas pelos vereadores e fortaleceria a democracia participativa, de modo que os Conselhos eram considerados estratégicos. A descentralização promoveria o "direito à cidade" e a inclusão do cidadão contra o "urbanismo do apartheid" ao universalizar serviços públicos (Sposati, 2001; entrevista 3). As políticas públicas seriam integradas à realidade local e reorganizariam a gestão municipal apoiada em instâncias de poder local (Donato, 2006).

Para Garibe (2004; 2006), a descentralização ampliaria a autonomia orçamentária das Subprefeituras, a participação popular incentivaria o controle social e haveria maior integração de políticas públicas. A descentralização de fato (poder local de decisão e recursos disponíveis) e o território como fator de gestão eram dois outros princípios (Donato, 2006). O governo não precisaria de 
intermediários para relacionar-se com os cidadãos, pois como as Subprefeituras seriam "centros regionais com poder de decisão e responsabilidade". O poder executivo municipal seria mais permeável aos grupos sociais que interagem com a cidade.

Os Conselhos seriam estratégicos no redesenho da gestão municipal, uma vez que teriam competências deliberativas, consultivas e fiscalizatórias sobre as Subprefeituras e a Câmara de Vereadores. Para Borja (1984), a descentralização e participação cidadã expressam o poder local visando reduzir a influência do aparato não democrático para a política aproximar-se da população. Todavia, as experiências de descentralização pouco renovaram a forma de fazer política ao reproduzirem meios tradicionais de dividir poder, pois a gestão local mais espelha a composição política do ayuntamiento do que os interesses da sociedade. Daí a relevância de identificar os atores políticos favoráveis à descentralização como forma de democracia local e aqueles interessados em manter o "caciquismo". Este é o assunto da próxima seção.

\section{O Conselho de Representantes: a berlinda entre a inovação e a política tradicional}

Os Conselhos estão previstos na Lei Orgânica Municipal de São Paulo, promulgada em 1990 (artigos 54 e 55). Desde o início da década de 1990 até o ano 2000 foram propostos quatro projetos para regulamentá-los, sendo três de vereadores do PT. Para este partido, estes fóruns eram peças políticas chave para controlar a gestão nas Subprefeituras e um mecanismo de participação social para gerar pressão sobre o governo (Donato, 2006). Em linha com Weir (1992) e King (1992), seriam pontos de inflexão na relação entre as regiões da cidade e o governo local, além de promoverem o desenvolvimento de novas instituições políticas em nível municipal. Conforme a Coalizão Muda São Paulo (2000), o PT lutaria para lidar com as raízes da corrupção e do autoritarismo que dominavam a Câmara Municipal. Os Conselhos contribuiriam para reformular um dos poderes do Estado que tinha sido alvo de denúncias sistemáticas de corrupção. Para Marta Suplicy (2002, p. 118-119), candidata do PT na eleição municipal em 2000 :

“[...] o Conselho de Representantes terá uma função muito clara e específica, como é a fiscalização. Por meio da atuação dos cidadãos acabará a influência do vereador para conseguir "favores especiais" nos bens e serviços públicos. Todo o tipo de corrupção deverá acabar (...). Assim, por meio dos Conselhos de Representantes a população poderá controlar a forma de atuação da administração pública e seus funcionários [...]. A população terá poder para controlar cada passo do subprefeito, cada passo da prefeita ou do prefeito".

Em julho de 2004 foi aprovada a Lei n. 13881, de 30 de julho de 2004, que criou os Conselhos, reconhecendo-os como órgãos autônomos para representar a sociedade civil, exercer controle social, supervisionar as ações e gastos públicos e propor melhorias nas políticas públicas nos bairros. Deveriam apoiar práticas democráticas, respeitar a autonomia dos movimentos sociais, participar no planejamento local, elaborar a proposta orçamentária e supervisionar sua execução juntamente com o Orçamento Participativo. O Subprefeito deveria promover encontros bimestrais com os Conselhos para analisar a implantação do plano de ação. Conforme Immergut (1992), conhecer a forma com as instituições políticas são concebidas é fundamental, pois ela constrange o comportamento dos atores políticos.

Mas, propostas como estas que ampliavam o papel da sociedade para fiscalizar os Subprefeitos, não eram bem vistas por vereadores atuantes nos bairros, pois temiam que sua influência e seu poder sobre as Subprefeituras e clientelas locais diminuíssem (entrevistas 1 e 5). Chocaram-se duas concepções da democracia: alguns vereadores apresentando-se como "representantes do povo" e outros, sobretudo do PT, como aliados dos movimentos sociais. A disputa entre essas duas posições exemplifica os efeitos que podem decorrer de ações inovadoras que enfrentam interesses dos atores em domínios de políticas (Hall, 1993).

Este debate expressou uma divergência entre os atores políticos sobre como exercer o controle social e fiscalizar o poder público nas regiões. Ademais, a criação dos Conselhos exemplificou os impasses do governo para implementar as Subprefeituras, tal como proposto na eleição municipal em 2000 (entrevista 3). Com efeito, as ressalvas apresentadas por Weir (1992) são elucidativas: a forma de gerir uma política pode criar problemas de tramitação no governo, especialmente se vem a ser complexo obter consenso sobre as mudanças administrativas apoiadas em novas ideias.

Nesse ponto da discussão é importante associar o debate sobre os Conselhos com a formação da coalizão de apoio do governo na Câmara Municipal, e como esse processo fortaleceu a oposição dos vereadores contra esse fórum. Conforme o programa de governo, a forma como os vereadores historicamente se apropriaram das regiões impossibilitava separar o Executivo e o Legislativo na gestão municipal. Caberia ao parlamento melhorar os projetos do governo, supervisionar o Executivo e, especialmente, lidar com temas globais da cidade. Nos territórios, a gestão com maior controle social seria responsabilidade das Subprefeituras (entrevista 2). Mas, para compreender como essa inovação institucional foi proposta pelo governo, importa conhecer o processo político subjacente às suas decisões (Immergut, 1992).

No entanto, o governo priorizou a construção de sua maioria parlamentar para evitar o isolamento político ocorrido no primeiro mandato do PT de 1989 a 1992. No início, o governo petista era apoiado por 19 vereadores (16 do PT e 3 do Partido Comunista Brasileiro (PCdoB), além de dois vereadores do Partido Socialista Brasileiro (PSB) que, em princípio, também eram aliados (Martins, 2001). No começo de 2002, segundo ano de gestão, diante da dificuldade em aprovar seus projetos na Câmara, o governo buscou ampliar sua coalizão de apoio. Até abril desse mesmo ano, o governo obtivera o apoio do Partido do Movimento Democrático Brasileiro (PMDB) (seis vereadores) e da bancada do Partido Liberal (PL) (três vereadores) com negociações que já envolviam cargos nas regiões. Com o PSB, a base governista de 30 parlamentares se tornou majoritária (a Câmara tem 55 vereadores).

Não é demais recordar que um dos mais poderosos fatores determinando como grupos definem seus interesses em políticas, e em quais alianças entram, é a organização das instituições políticas (Weir, 1992). Nesse caso, com as prerrogativas que possui, a Câmara Municipal é uma instituição que pode ser decisiva como 
veto player ou aliado estratégico para governos aprovarem seus projetos. A trajetória histórica da relação entre Executivo e Legislativo municipal, mesmo em governos como Paulo Maluf (1992-1996) e Celso Pitta (1997-2000), apoiados por bancadas majoritárias, caracterizou-se por atender os interesses dos vereadores, notadamente os mais fisiológicos. O processo político subjacente às decisões governamentais (Immergut, 1992) vinha sendo marcado por essa característica central.

O governo Marta Suplicy planejava ampliar sua coalizão de apoio no parlamento, para qual a criação das Subprefeituras foi o estímulo necessário para trocar apoio por cargos nas regiões. Os vereadores da coalizão dominante (PT e demais partidos) temiam perder influência em seus redutos eleitorais, pois a nomeação dos Subprefeitos pelo Executivo poderia fortalecer as lideranças de bairro. A opção do governo foi franquear a indicação dos Subprefeitos aos vereadores, o que reduziu o alcance inovador da descentralização quanto à forma de fazer política ao reproduzir meios tradicionais de dividir poder (Borja, 1984).

Assim, ao aprovar as Subprefeituras, o governo também fez desse ato um marco para consolidar sua política de alianças no parlamento, a partir de julho de 2002 (entrevista 8). Ao mesmo tempo, o governo mostrou que a democracia participativa não seria priorizada na gestão local, mas sim a divisão de poder com os vereadores, como podemos observar na fala de um Subprefeito sobre a influência dos vereadores nas estruturas locais de gestão:

[...] A indicação é sempre política e sempre será assim, e ai não é um problema a indicação do vereador da região, pois ele fiscaliza até mesmo o Subprefeito se ele agir mal [...]. Vereador é votado para ser alguém a favor do povo que deve ter no vereador o seu apoio como se fosse representante distrital e ai entra a indicação do Subprefeito pelo vereador (entrevista 4).

A partir daquele momento, a base aliada no parlamento passou a ser constituída pelo PL (três vereadores), Partido Trabalhista Brasileiro (PTB) (três vereadores), Partido Democrático Trabalhista (PDT) (três vereadores), Partido Geral dos Trabalhadores (PGT) (um vereador), Partido da Frente Liberal (PFL) (um vereador), Partido Progressista Brasileiro (PPB) (dois vereadores), PMDB (quatro vereadores), Partido Popular Socialista (PPS), PSB (dois vereadores) e o Partido da Reedificação da Ordem Nacional (PRONA) (um vereador). Com os 19 vereadores do PT e PCdoB, o governo construiu uma coalizão de 42 vereadores. Todas essas bancadas, com destaque para o PT, tiveram vereadores contemplados com indicações nas Subprefeituras. Mesmo vereadores teoricamente de oposição como os do PFL, PPB e PRONA votavam a favor do governo.

Assim, para o que importa como apoio ao argumento central do artigo, algumas considerações são relevantes. Em primeiro lugar, se conformou uma associação de interesses de vereadores que há várias legislaturas eram base de apoio governamental, alguns desde a gestão Jânio Quadros-PTB (1985-1988), passando pelas

2 Para maiores informações sobre a forma como se configurou a coalizão política dominante com todos os partidos políticos após a aprovação das Subprefeituras, comparativamente à coalizão eleitoral apenas formada pelo PT e PCdoB ver Grin, E. J. Construção e desconstrução das Subprefeituras gestões Paulo Maluf-PPB (1992-1996) e Celso Pitta-PPB (19972000). Entre esses parlamentares estavam filiados do PL, PPB, PDT, PGT, PPS, PTB e PMDB, cujo suporte aos governos sempre se associou com a manutenção de sua influência política nas regiões ${ }^{2}$. O vereador Toninho Paiva $(\mathrm{PL})$, membro do chamado "Centrão" na Câmara Municipal, e historicamente influente na região da Penha, expressou bem a posição dos parlamentares: "O PT não entendeu que não tem maioria na Casa e eles precisam de uma base de sustentação" (Estado de São Paulo, 11/07/2002). Em 2005 este vereador estava na base de apoio do governo José Serra (PSDB) e manteve influência regional. Assim, a inovação institucional das Subprefeituras acabou tendo sua trajetória restringida (Weir, 1992) ao servir para reposicionar os vereadores como integrantes da base governista, ademais de manter a política do "caciquismo local" (Borja, 1984).

Se a proposta de controle social nas Subprefeituras poderia pôr em risco a estratégia de reprodução política desses vereadores, seus votos no parlamento seguiam sendo a principal moeda de troca. O governo do PT aceitou essa barganha ao priorizar a construção da governabilidade para aprovar projetos na Câmara. Este grupo será chamado de vereadores "tradicionais", pois esse foi seu modus operandi predominante, visto que "a pressão se dava para votar questões na Câmara, era exatamente isso. Todo vereador que tem uma Subprefeitura na mão é um instrumento poderoso e transforma pequenas coisas como uma generosidade ou pequenos favores" (entrevista 5). Portanto, conforme Olsen (1984) e Thelen e Steinmo (1992), o PT como partido da Prefeita expandiu os "direitos" de participação de parlamentares fisiológicos, o que alterou a divisão de poder e o cenário institucional em desfavor do discurso que embasava o projeto das Subprefeituras.

Em segundo lugar, o governo e os vereadores do PT não tinham convicção política nem uma proposta clara sobre o papel dos Conselhos, mas apenas uma ideia geral de democracia participativa. Ainda assim, houve um cálculo político do governo que apoiar canais de participação mais direta seria uma via para pressionar os vereadores, o que ajudaria a reduzir o custo da barganha. A democracia participativa não só seria mais "avançada", mas serviria para pressionar os edis em fóruns onde os movimentos sociais costumavam ser mais simpáticos ou francamente adeptos ao PT.

As indefinições do governo e do PT sobre os Conselhos associaram-se à necessidade atribuída pelo Executivo para compor sua base de apoio no parlamento. Nesse contexto, três grupos se formaram no interior do partido e do governo. No núcleo político do governo predominaram os "pragmáticos" favoráveis à negociação com os vereadores protagonistas do "toma-lá-da-cá" tradicional na política municipal. Na bancada do PT, havia os "caronas", um grupo de vereadores que não eram apoiadores entusiastas desses fóruns, mas estavam pouco à vontade para expressar sua oposição pelo desgaste que geraria junto aos movimentos sociais.

na cidade de São Paulo no governo Marta Suplicy, Revista de Sociologia e Política, v. 23, n. 55, 2015. 
Havia ainda os "democráticos", grupo formado por vereadores de "opinião" e aqueles com trajetória política ligada a lutas sociais nos bairros, que defendiam ampliar o controle social. Também participavam desse grupo os Subprefeitos, militantes do PT nas regiões e movimentos sociais alinhados ao partido. Mesmo sem ser homogêneo, no grupo predominava uma visão pró-Conselhos e de democratização do poder local.

A luta entre representação política e democracia participativa acabou sendo o mote para o governo construir sua coalizão política, mesmo com a desconstituição da proposta dos Conselhos. O "pragmatismo" de setores do PT, aliados aos "caronas", ao fim e ao cabo, acabaram apoiando os interesses tradicionais dos vereadores nas regiões, o que consolidou a oposição a esta proposta. Com efeito, a ressalva de Borja (1984) de que a gestão dos bairros corre o risco de refletir mais a composição política do ayuntamiento do que os interesses da sociedade tornou-se realidade.

A "diminuição" que esse processo geraria no parlamento sofreu a oposição explícita de alguns vereadores e o apoio frágil de outros, enquanto o governo e o PT, ao recuar de suas intenções iniciais, acabaram por limitar o alcance dos Conselhos. A governabilidade no parlamento prevaleceu sobre o estímulo ao controle social nas regiões (entrevista 8). Assim, a implantação das Subprefeituras não foi acompanhada dos Conselhos como suporte à descentralização política de poder (Garibe, 2004; 2006; Donato, 2006; Sposati, 2001). Os Conselhos, que fiscalizariam o parlamento conforme 0 programa apresentado nas eleições municipais e por dirigentes governamentais, "murcharam" na lei que os aprovou em julho de 2004, como será visto a seguir.

\section{A história da desconstrução do Conselho de Representantes}

Os Conselhos foram inicialmente propostos, em janeiro de 2001, pelo Instituto de Estudos Avançados (IEA) da Universidade de São Paulo para a Mesa Diretora da Câmara Municipal. Justificava-se que as Subprefeituras e os Conselhos inovariam o exercício do poder municipal no tocante à eficácia, governabilidade e participação cidadã para democratizar a política. Por não legislarem, não seriam pequenos parlamentos, mas criariam novos canais de participação da sociedade junto aos poderes Executivo e Legislativo. O projeto, também apresentado à prefeita Marta Suplicy, destacava a importância de não se frustrar essas expectativas junto à população dos bairros. Contudo, os embates expressaram duas visões opostas: vereadores "tradicionais" associados a petistas "pragmáticos" no governo e os "caronas" na Câmara Municipal contra os "democráticos". Nesse contexto de interesses conflitantes formaram-se as coalizões no interior do processo político que foi desencadeado (Thelen e Steinmo, 1992) e teve seu desfecho final em 2004.

O estudo do IEA embasou o projeto de lei apresentado pela Mesa Diretora da Câmara Municipal. Pela proposta, os membros dos Conselhos seriam eleitos diretamente (2/3 de moradores dos distritos e 1/3 de cidadãos com endereço de trabalho na região). Poderiam ser indicados cidadãos apoiados por no mínimo 100 pessoas domiciliadas na região ou ONG de interesse público e social. O projeto de lei 001/2001 previa instalar uma "Ouvidoria e Recursos da Cidadania" para atender os cidadãos, receber pleitos e denúncias de irregularidades. Esta área foi suprimida na versão final da lei aprovada em julho de 2004, apesar de uma emenda do vereador Carlos Neder (PT), favorável à sua implantação.

No interior da Câmara Municipal, até 2004, o projeto nunca chegou ao plenário para ser votado, pois as principais arenas de debate foram as comissões permanentes. Nessas instâncias internas travou-se a disputa dos principais grupos de vereadores acima caracterizados. Nas comissões, a composição com maioria favorável ou contrária aos Conselhos, a hegemonia dos cargos mais relevantes (Presidência e Secretaria) e as posições jurídicas das áreas técnicas de apoio eram variáveis políticas e institucionais que dificultavam a tramitação da matéria (entrevista 6.). Tornou-se muito difícil para os apoiadores da proposta obterem consenso em torno dessa mudança institucional (Weir, 1992).

Por exemplo, na Comissão de Política Urbana, um parecer de dezembro de 2001 defendia os Conselhos como meio de garantir a representatividade das forças políticas e sociais nos bairros. Assim seria possível implantar a democracia representativa e participativa, fiscalizar os gastos públicos e inovar no controle social sobre a gestão municipal. Nessa linha seguia a emenda n. 01 ao projeto de lei substitutivo n. 02, proposta em julho de 2004 pelo vereador Carlos Neder (PT), vinculado ao movimento social da saúde, defendendo que os Conselhos fossem sediados nas Subprefeituras. Caberia ao Poder Executivo prover os recursos materiais, humanos e financeiros necessários ao seu funcionamento. Essa comissão era presidida por uma vereadora de "opinião" do PT e secretariada por uma vereadora do PCdoB vinculada aos movimentos sociais da zona leste da cidade.

Em outro extremo, um parecer da assessoria técnica da Comissão de Constituição e Justiça da Câmara Municipal, em março de 2001, indeferiu a proposta dos Conselhos. Sempre é bom lembrar a relevância dessa comissão, pois ela possibilita a admissibilidade de projetos em sua legalidade e constitucionalidade, o que faculta ou não o seu debate. Argumentou-se que o projeto visava criar "um novo titular de iniciativa legislativa, matéria de cunho constitucional e hipótese não prevista na Carta Maior de 88, tampouco na Lei Orgânica do Município de São Paulo".

A tese era que os Conselhos não poderiam ter autonomia para alterar seu Regimento Interno sem anuência da Câmara Municipal, pois deveriam ser criados por Decreto Legislativo. Negou-se a proposta de que a Mesa Diretora da Câmara tivesse que instalar Comissões Parlamentares de Inquérito para apurar irregularidades denunciadas pelos Conselhos. Aceitar tal prerrogativa do Conselho foi considerado uma "ofensa ao princípio da representação próprio da democracia representativa" (Comissão de Constituição e Justiça da Câmara Municipal). Para Lowi (1964), o lócus institucional influi na capacidade de os grupos influenciarem as políticas, e a forma como seus interesses são definidos leva-os a construir coalizões políticas. A Comissão de Constituição e Justiça, nesse sentido, se constituíram em um "filtro" regimental, mas também politico, à proposta. 
De forma geral, a justificativa era que a "edilidade não poderia ser compungida a instalar CPI ao seu alvedrio, sob pena de ofensa ao princípio da independência do Poder Legislativo". Parecer idêntico repetiu-se em junho de 2001 em relação ao projeto de lei substitutivo de um vereador do PT da ala "democrática", vinculado aos movimentos sociais em Pirituba, bairro da zona norte de São Paulo. Nessa comissão, seu presidente era um vereador do PT mais próximo dos "pragmáticos" do núcleo político do governo e mais afinado com os parlamentares "tradicionais". Gradativamente os "democráticos" tornaram-se minoritários nessa arena. Portanto, importa entender como os grupos inserem seus interesses nas políticas e como esse processo pode criar conflitos nas instituições (Lowi, 1964).

Assim, os pareceres contrários da assessoria técnica dessa comissão eram uma roupagem legal para não expor a real oposição política. Ainda que de 2002 a 2004 essa comissão protagonizasse mudanças de opinião, pois sua composição alterou-se, a hegemonia dos "tradicionais" se consolidou, fazendo com que vários obstáculos sobre a legalidade e a constitucionalidade dos Conselhos fossem apresentados. Apenas para ilustrar, em 2002, a presidência foi ocupada por vereador do PR que se opunha aos Conselhos, dessa forma, havia um "democrático" e um "carona". Este vereador era "contra o conselho [de Representantes] desde o primeiro momento porque acho que ele vai tirar o papel do vereador" (Folha de São Paulo, 16/07/2002). Em julho de 2004, com suas indicações asseguradas nas Subprefeituras, votou a favor da lei que criou os conselhos. Conforme Immergut (1992), atores políticos formulam suas estratégias conforme os lugares ocupados no desenho institucional. Todavia, se o governo desejasse priorizar esse tema, diante da importância dessa Comissão, talvez atuasse para mudar a sua composição (entrevista 1).

Embates similares ocorreram em outras comissões, como por exemplo, Administração Pública e Finanças e Orçamento. Para os fins desse artigo esse debate representou o pano de fundo da clivagem política que opôs apoiadores e opositores quanto à aprovação da matéria. Sobretudo para os "tradicionais", os Conselhos poderiam incubar novas lideranças comunitárias, o que se chocava com seus interesses locais, o que também incluía vereadores do PT. Tais parlamentares viam-se como os únicos intermediadores políticos nas regiões e temiam que sua influência se esvaziasse com a ação dos conselheiros (entrevistas 3 e 6). A sequência inovadora da política (Weir, 1992), no caso os Conselhos, ao ser freada, cedeu espaço para seguir sendo capturada pela influência clientelista dos vereadores "tradicionais" (Sposati, 2001), o que se opunha ao programa de governo eleito em 2000.

Em 2002, essa visão era voz corrente entre os vereadores que rejeitavam explícita ou veladamente o projeto. Por exemplo, a vereadora Myryam Athiê (PMDB) declarou à Folha de São Paulo em 04/04/2002: "sou contra o conselho, acho que o conselheiro não pode substituir o vereador, à medida que dou esse poder para ele, qual vai ser o meu papel?" O vereador Antônio Carlos Rodrigues $(\mathrm{PL})$ era "contra o conselho desde o primeiro momento porque acho que ele vai tirar o papel do vereador" (Folha de São Paulo,
16/07/2002). Assim, em situações como essas, onde grupos têm interesses conflitantes, é necessário examinar o processo político a partir do qual se formam coalizões (Thelen e Steinmo, 1992).

Nesse cenário, como o governo temia que a discussão combinada das Subprefeituras e dos Conselhos travasse a votação da primeira matéria, considerada prioritária, freou o debate do segundo tema, mesmo negando a integração de ambos conforme o programa apresentado na eleição municipal em 2000.

Objeções como essas contribuíram para que a inovação proposta de serem os Conselhos integrados por indivíduos eleitos diretamente nas regiões fosse transformada, na lei aprovada em 2004, em um órgão composto por 27 integrantes com nove vagas reservadas aos partidos políticos presentes na Câmara Municipal, conforme a proporcionalidade de suas bancadas. Um terço dos membros, ao invés de ser escolhido diretamente, seria eleito pelos diretórios zonais dos partidos, ainda que tivesse que pertencer a qualquer conselho, ONG ou entidade local.

Justificou-se a necessidade de fortalecer os partidos políticos como base da democracia e canal de expressão das demandas da sociedade. Contudo, ao invés de os partidos escolherem seus candidatos e submetê-los ao escrutínio popular, se garantia um terço das vagas para aqueles que tivessem filiação partidária, o que suprimiu a eleição direta. Esta mudança exemplifica a argumentação de Weir (1992) sobre inovação institucional limitada e os desafios colocados à "sequência de uma política".

Considerando que os partidos tinham vereadores com base eleitoral local, pode-se conjecturar que esses atuariam para eleger os demais 18 membros dos Conselhos. Portanto, tem-se uma medida da vantagem que os parlamentares com influência nas regiões passariam a desfrutar. Isso porque, nos bairros, os vereadores geralmente seriam os atores mais influentes para indicarem candidatos às vagas de conselheiros. Estes, em troca, poderiam apoiá-los em suas campanhas eleitorais, além desse suporte reduzir a possibilidade de comportamentos concorrentes com os parlamentares.

Este desenho dos Conselhos contrastava com a concepção original das Subprefeituras de que a proximidade do poder público junto à população reduziria a captura política dos vereadores da gestão local. Paradoxalmente, superar a influência dos vereadores nas regiões se tornou ainda mais difícil com a descentralização posta em marcha, pois aumentou os recursos financeiros e número de cargos a serem nomeados nos territórios. Em linha com Hall (1993), o passado das políticas ajuda a analisar como os atores políticos atuam e pode explicar por que ações inovadoras enfrentam interesses dos atores quando da sua implementação.

Quanto aos Conselhos, eram indesejados, sobretudo pelos vereadores "tradicionais", que enxergavam nesse fórum um concorrente para propor iniciativas legislativas, organizar audiências públicas e estimular a população a fiscalizar os Subprefeitos que eram, na sua imensa maioria, indicados pelos parlamentares. Para os vereadores, essas eram prerrogativas apenas suas, pois se viam como os únicos representantes legítimos da sociedade. Ademais, expandir a responsabilidade do Subprefeito 
perante os Conselhos poderia afetar seu padrão de influência local e prejudicar o tratamento de suas demandas.

Sobre as indicações dos vereadores, o novo subprefeito da Freguesia do Ó disse à Folha de São Paulo (10/01/2003): "Eu não vejo problema nisso porque ninguém melhor do que um vereador da região para saber dos problemas dos bairros". O subprefeito creditou sua indicação aos vereadores José Viviani Ferraz (PMDB) e Antônio Baratão (PDT), sobretudo o primeiro "porque ele é da região. É um vereador que vota com a prefeita, né? O Baratão, que também é da região, também vota[com o governo]". Tais informações foram confirmadas ao autor (entrevista 4). Portanto, o projeto dos Conselhos caminhou longe de ser um apoio para criar "centros regionais de poder" mais permeáveis às populações nos bairros (Donato, 2006).

Quanto à fiscalização, o projeto original previa duas atribuições suprimidas na lei aprovada em 2004: a) preparar audiência pública para aprovar Relatório de Avaliação e Fiscalização da Ação Municipal com o Subprefeito e a Comissão de Administração Pública da Câmara Municipal e; b) acompanhar, com os delegados do Orçamento Participativo, a aplicação das dotações orçamentárias. Os Conselhos dividiriam com o parlamento a fiscalização das Subprefeituras. De forma similar, em fevereiro de 2001, o vereador José Laurindo (PT) propôs ampliar suas atribuições em relação à Lei de Diretrizes Orçamentárias. Caso a Câmara verificasse a inexistência de parecer dos Conselhos, a tramitação da matéria seria interrompida. Também estendia a ação dos Conselhos para apresentar à sociedade Relatórios de Avaliação de Resultados e de Fiscalização.

Por essa proposta desse vereador, os Conselhos poderiam apresentar sugestões de projetos de lei e decretos legislativos à Mesa da Câmara e esta deveria encaminhar a tramitação. Audiências públicas poderiam ser convocadas para subsidiar os Conselhos na elaboração dos relatórios e os poderes Executivo e Legislativo deveriam repassar informações no prazo máximo de 30 dias para não incorrerem em improbidade administrativa. Dispunha sobre as atribuições dos conselheiros, mediante petição fundamentada, para apurar irregularidades cometidas por Subprefeitos ou servidores. O Conselho poderia votar moção de desconfiança contra os Subprefeitos, justificando-a em parecer enviado ao Prefeito, além de requisitar a presença de diretores de Secretarias ou do Subprefeito.

As mudanças no projeto de lei original foram apresentadas no substitutivo 02/2004 que parece ter sido o acordo possível com todas as bancadas, inclusive com votos da oposição, sobretudo do PSDB. Contudo, o resultado foi que os Conselhos não avançaram com o "empoderamento" da população nos bairros. Haveria oportunidade de o cidadão ver por que a política pública não ocorria diante da confusão dos vereadores querendo ocupar o papel do Poder Executivo ao indicar pessoas, elaborar projetos e emendas orçamentárias sem conhecer as funções de gestão. Além desses obstáculos, houve falta de vontade política do governo para buscar apoio a esse novo formato de gestão da cidade (entrevista 1). Com efeito, a forma como se estrutura uma política é chave para os atores políticos e seus interesses, pois pode gerar obstáculos para reorganizá-lo em novas bases (Immergut, 1992).

Nesse sentido, se nas Subprefeituras os vereadores indicavam Subprefeitos, os Conselhos eram tidos como um risco por reduzir o poder local dos parlamentares. Por tal razão, manter influência política junto às Subprefeituras era estimulado pelos vereadores e aceito pelo governo; aumentar o controle social sobre as mesmas não tinha o mesmo apoio dos parlamentares, o que fez o governo recuar de sua proposta inicial. Assim, a inovação proposta pelos Conselhos foi traduzida em linguagem que a tornou palatável para a decisão política, mesmo modificando suas noções originais (King, 1992).

A fala de um dos entrevistados é cristalina sobre esse "cotidiano da política" e seu efeito para limitar o alcance de inovações que ponham em risco as práticas institucionalizadas do "toma-lá-da-cá":

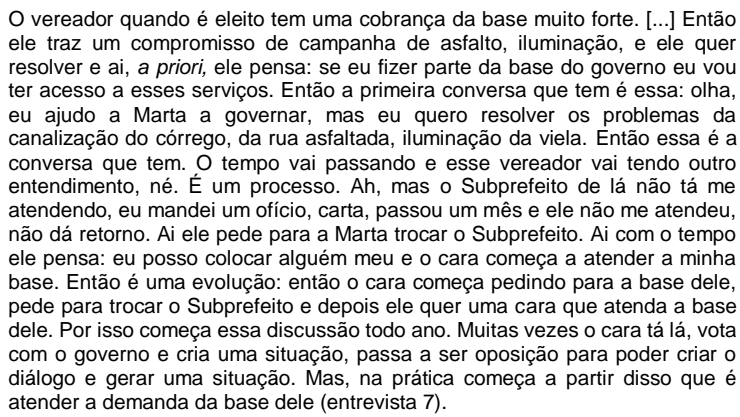

Uma vez que a política de alianças apoiou-se nesse tipo de expediente, estancou o avanço das Subprefeituras ao abrir espaço para pessoas descomprometidas com o projeto político (entrevistas 1 e 5). Esta divergência também ocorreu na base aliada do governo, pois o apoio a essa prática não era consenso entre os vereadores, sobretudo do PT. A esse respeito, Sanchéz (2006, p. 55), Coordenador Municipal do Orçamento Participativo, pergunta:

"Como fazer para governar de forma efetivamente democrática? É
um tema que apenas conseguimos desenhar aqui na cidade, pois
não completamos o processo. A ideia das Subprefeituras tinha suas
limitações, pois não houve a implementação dos conselhos de
representantes como expressão do direito à participação - um dos
propósitos centrais do projeto da descentralização. Além do mais, o
atual governo municipal ${ }^{3}$ não quis enfrentar, de fato, a constituição
dos conselhos de representantes, o que, a bem da verdade,
também, era um elemento de conflito entre nós. Provavelmente, a
ampla coalizão de partidos e parlamentares que sustentava o
governo Marta Suplicy não tolerasse essa convivência. Como
faríamos, então, para governar com ela: ouvindo a população ou o
vereador do bairro ou do distrito?"

Nesse contexto, a oposição dos vereadores se manifestou na tramitação da lei das Subprefeituras. Os Conselhos, peça da engrenagem política da descentralização, foram suprimidos para o governo obter votos para aprovar a criação das Subprefeituras. Essa dificuldade foi admitida pelo vereador Carlos Neder (PT), pois alguns vereadores condicionavam aprovar as Subprefeituras a não aprovação do Conselho de Representantes. Esta possibilidade também foi admitida pelo líder do governo, vereador José Mentor (PT). (Folha de São Paulo, 04/04/2002). As manobras dos 
vereadores, sobretudo os "tradicionais", dadas as ameaças de rever suas estratégias se seus interesses não fossem considerados (Thelen \& Steinmo, 1992), teve um impacto decisivo na trajetória institucional e política dos Conselhos.

O Conselho era um princípio político, mas não um projeto essencial naquela conjuntura. Se as Subprefeituras descentralizariam o poder executivo, os Conselhos descentralizariam o poder legislativo. Essa posição é um exemplo de outro problema que o governo tinha para tratar desse tema: mesmo se tratando apenas de proposta política, não havia acordo interno sobre a o alcance da democracia participativa, em sua relação com a lógica da democracia representativa. Por exemplo, "os Conselhos deveriam se restringir ao controle e fiscalização das Subprefeituras ou poderiam acrescer a essas funções a proposição legislativa?" (entrevista 1). Já as Subprefeituras eram consideradas estratégicas e a objeção dos vereadores "tradicionais", associada à ação dos "pragmáticos" no governo influiu para separar os dois projetos. Para Tatto (2006, p. 315), o governo tinha:

"Um timing para aprovar o conselho de representantes das Subprefeituras, medido pela correlação de forças na Câmara - pois o conselho era uma iniciativa exclusiva do legislativo e não da Prefeitura -, assim, fomos criticados publicamente por certas organizações e, quando conseguimos avançar, novas queixas surgiram, pois o conselho contemplava a participação de representantes dos partidos. Há que se entender que essa é uma concepção atrasada, pois é inconsequente termos uma sociedade organizada e um conselho que quer excluir a participação partidária, seja ela qual for [...]. A concepção de democracia que se defende requer partidos organizados, sólidos e programáticos".

Mas a posição do governo, em 2004, era distinta daquela apresentada na campanha eleitoral sobre o papel fiscalizador dos Conselhos, inclusive sobre os vereadores. A mudança sobre a forma de eleger os conselheiros foi uma concessão do governo aos vereadores para manter sua coalizão de apoio. A correlação de forças favorável à aprovação do projeto na Câmara Municipal reforça o argumento de que, no caso dos Conselhos, a solução negociada foi um recuo da proposta inicial face às resistências dos vereadores. Por isso, o projeto foi debatido por quatro anos, foi aprovado em julho de 2004 e teve sua primeira eleição prevista para abril de 2005, mas ocorreu, de forma distinta da Lei, apenas em dezembro de $2013^{4}$. Coube aos partidos políticos, e aos vereadores, em especial, os "tradicionais" e "pragmáticos", um papel crucial nesta "tradução" (King, 1992) de uma visão modificada sobre os Conselhos.

Em suma, o impasse na aprovação dos Conselhos expressou a disputa sobre duas formas de ação política: vereadores que procuravam manter a influência política, contra outro modelo centrado no controle social. As concessões feitas pelo governo reduziram o alcance da proposta inicial para democratizar o poder local. O peso das instituições políticas (Câmara Municipal) e dos atores políticos (vereadores) limitou a implantação inovadora dos Conselhos como um fórum de democracia participativa. Não

\footnotetext{
${ }^{4}$ O governo do PT iniciado em janeiro de 2013 regulamentou os Conselhos por decreto porque desde 2005 vem processando uma ação de inconstitucionalidade sobre o projeto de lei que criou os Conselhos em 2004. Em função desta indefinição legal, mas em relação ao compromisso assumido pelo novo prefeito da PT Sobre a implementação dos Conselhos, acrescentou as pressões dos movimentos sociais ligados à PT, uma precária
}

implantar os Conselhos de Representantes foi um recuo do governo em direção à lógica da vereança, pois:

"Votar o Conselho de Representantes era por o dedo na ferida do lado de cá das Subprefeituras e não fazê-lo já mostrava que, poxa, vai até certo ponto, afinal de contas esse governo tem que votar coisas na Câmara e não vai correr riscos por causa disso. [...] O que tá colocado lá, de fato, é uma descentralização não só administrativa, mas de poder, e o Conselho de Representantes era explícito e direto nisso [...]". (entrevista 8)

\section{Conclusão}

Pelo discurso do PT, a descentralização construiria o "poder local" e a democracia participativa por meio das Subprefeituras e dos Conselhos. Este artigo discutiu como e por que esse projeto foi desconstruído diante da prioridade que o governo conferiu à montagem de sua "coalizão política dominante". Como lembra Mollenkopf (1994, p. 5), "para permanecer dominante, ela deve ser capaz de administrar as tensões que inevitavelmente surgem das diferenças de interesse entre sua base eleitoral e seus aliados no governo". O artigo, à luz da literatura utilizada, discutiu como e por que a implantação do Conselho de Representantes no governo Marta Suplicy (2001-2004) não logrou êxito.

Embora existam "interesses contraditórios", ao construir essa coalizão, o Executivo divide seus oponentes, secundariza velhas clivagens políticas e refaz alianças em torno de uma centralidade de poder encabeçada pelo Prefeito. Acomodam-se interesses nem sempre coincidentes dos atores políticos na coalizão dominante. Daí a importância de se conhecer a forma como se constitui esse arranjo político a partir das "regras do jogo" da competição política (Mollenkopf, 1994). Diante de um puzzle político, ao buscar equilibrar posições políticas divergentes, o governo do PT o fez em detrimento dos Conselhos, ciente que os interesses dos vereadores nos territórios seguiam predominando na política municipal.

A aceitação desta opção política não é desprezível frente ao discurso da democracia participativa proposto na campanha eleitoral. Todavia, o governo cedeu espaço às ditas práticas tradicionais instituídas na política municipal de transformar os territórios em recurso político para constituir coalizões de apoio parlamentar. A defesa da democracia local, e sua convivência com as instâncias de democracia representativa, diluíram-se em favor da "lógica da vereança" no parlamento e sua extensão nas Subprefeituras. A "inovação" da descentralização política e administrativa com controle social acabou "limitada" em um dos aspectos mais radicais do discurso democrático petista: a implantação dos Conselhos.

Práticas políticas institucionalizadas na ação dos vereadores constrangeram a forma como se deu a construção da política de alianças no parlamento. $\mathrm{O}$ arranjo político resultante favoreceu tendências conservadoras na formação e atuação da coalizão dominante ao manter padrões prevalecentes de distribuir empregos e outros benefícios para atender os interesses dos vereadores.

solução legal os instituiu por meio de um decreto. Mas esta foi a alternativa possível fundada para implementar a implementação de Conselhos com a votação de 1125 vereadores em dezembro de 2013 que iniciou suas atividades em janeiro de 2014 
Sendo tais iniciativas centralizadas no Prefeito, como ocorreu em São Paulo na gestão do PT, ela revelou as escolhas politicas e os mecanismos utilizados para se construir a base de apoio parlamentar. Por essa razão, o caso dos Conselhos mostra a relevância de se analisar os mecanismos internos de governo que servem de recursos para a construção de sua "coalizão política dominante" (Mollenkopf, 1994).

A prevalência institucionalizada de práticas políticas também constrangeu o governo a "limitar" sua agenda com a "mobilização do viés" que "filtrou" os temas do debate político para evitar controvérsias (Bachrach \& Baratz, 1962). Esse processo ocorreu na implantação das Subprefeituras, pois o Executivo acabou restringindo o escopo do projeto frente ao seu desenho inicial, ao buscar não conflitar com os interesses dos vereadores e recuar na implantação dos Conselhos, o governo definiu um "teto" para o alcance do controle social que seria exercido nos bairros e, também, sobre os próprios vereadores.

A forma como o governo construiu sua política de aliança gerou a convivência de duas lógicas políticas distintas nas Subprefeituras: incentivos à democracia participativa e os interesses dos vereadores. As duas formas de ação mobilizaram diferentes atores políticos, basearam-se em premissas distintas e criaram dinâmicas políticas particulares em cada bairro. Assim como cada Subprefeitura tinha um peso diferente no cálculo político da governabilidade, seus desenhos regionais se ajustaram aos atores políticos e seus interesses locais. A única semelhança entre todas as regiões é que os Conselhos se perderam no discurso do PT como meio de controle social.

Manobras e conflitos entre os atores políticos podem influenciar os parâmetros institucionais no interior dos quais esses interagem para defender suas posições, assim como os atores podem rever suas estratégias, caso seus interesses deixem de ser considerados. Estes são fatores de "dinamismo institucional" que mudam o balanço político do poder, geralmente quando velhas instituições são postas a serviço de novos fins (Thelen \& Steinmo, 1992). Assim foi no governo petista em São Paulo quando, na arena parlamentar, este recuou no debate sobre a criação dos Conselhos frente à contrariedade de vereadores "tradicionais", a disposição dos "pragmáticos" e o pouco interesse dos "caronas".

A inovação limitada dos Conselhos foi um resultado do peso das práticas políticas institucionalizadas como variáveis contextuais, que conformam as regras do jogo na política municipal. Com efeito, na política, mudar nem sempre significa renovar quando instituições tradicionais se mantêm fortes para constranger e limitar a ação dos atores políticos.

\section{Referências}

Abranches, S. H. (1988). Presidencialismo de Coalizão: o dilema institucional brasileiro. Dados - Revista de Ciências Sociais, 31 (1), 5-34.

Agência Estadão (2002, Julho11). Base aliada da ultimato à Marta. O Estado de São Paulo. Recuperado de: http://brasil.estadao.com.br/noticias/geral,base-aliada-da-ultimato-amarta,20020711p18521

Bachrach, P. \& Baratz, M. (1962). S. Two Faces of Power. The American Political Science Review, v. 56 (4), 947-952.

Borja, J. (1984). Descentralización: una cuestión de método. Revista Mexicana de Sociologia, 46 (4), 5-33.
Capucci, P. (2004). Subprefeituras em São Paulo: o menor é melhor?. In R. Garibe \& P. Capucci (Orgs.), Gestão local nos territórios da cidade: ciclo de atividades com as subprefeituras (pp. 19-24). São Paulo: Mídia Alternativa: Secretaria Municipal das Subprefeituras.

Castells, M. (1983). A Questão Urbana. Rio de Janeiro: Paz e Terra.

Castells, M. (1989). Cidade, democracia e socialismo. Rio de Janeiro: Paz e Terra.

Coligação Muda São Paulo (2000). Programa de Governo [Mimeo]. Partidos dos Trabalhadores, São Paulo, SP.

Reportagem local (2003, janeiro 10). Ex-subprefeito de Maluf assume defendendo indicações políticas. Folha de São Paulo. Cotidiano p. C4. Recuperado de: http://www1.folha.uol.com.br/fsp/cotidian/ff1001200312.htm Dahl, R. (2005). Poliarquia. São Paulo: Edusp.

Diniz, M. (2002, julho 16). Base aliada racha e não vota a criação de Subprefeituras. Folha de São Paulo. Cotidiano p. C4. Recuperado de: http://www1.folha.uol.com.br/fsp/cotidian/ff1607200207.htm.

Diniz, M. (2002, abril 4). Disputa por cargos trava subprefeituras. Folha de São Paulo. Cotidiano p. C4. Recuperado de: http://www1.folha.uol.com.br/fsp/cotidian/ff0404200220.htm.

Donato, A. (2006). A descentralização em São Paulo. In R. Gaspar, M. Akerman \& R. Garibe (Orgs.). Espaço Urbano e Inclusão Social: a gestão pública na cidade de São Paulo (2001-2004) (pp. 35-42). São Paulo: Editora Fundação Perseu Abramo.

Fernandez, J.C.A. \& Mendes, R. (2003). Subprefeituras em São Paulo e Políticas Públicas para Qualidade de Vida. São Paulo: Cepedoc Cidades Saudáveis/Mídia Alternativa.

Garibe, R. A descentralização do poder em São Paulo. In R. Garibe \& P. Capucci (Orgs.), Gestão local nos territórios da cidade: ciclo de atividades com as subprefeituras (pp. 25-34). São Paulo: Mídia Alternativa: Secretaria Municipal das Subprefeituras.

Garibe, R. Estado e descentralização. A descentralização em São Paulo. In R. Gaspar, M. Akerman \& R. Garibe (Orgs.). Espaço Urbano e Inclusão Social: a gestão pública na cidade de São Paulo (2001-2004) (pp. 25-34). São Paulo: Editora Fundação Perseu Abramo.

Grin, E. J. (2015). Construção e desconstrução das Subprefeituras na cidade de São Paulo no governo Marta Suplicy. Revista de Sociologia e Política, 23 (55), 119-145.

Immergut, E. M. (1992). The rules of the game: the logic of health policymaking in France, Switzerland, and Sweden. In S. Steinmo, K. Thelen \& F Longstreth (Orgs.). Structuring politics: historical institutionalism in comparative analysis (pp. 57-89). Cambridge: Cambridge University Press.

King, D. (1992). The establishment of work-welfare programs in the United States and Britains: Politics, Ideas and Institutions. In S. Steinmo, K. Thelen \& F. Longstreth (Orgs.). Structuring politics: historical institutionalism in comparative analysis (pp. 217-250). Cambridge: Cambridge University Press, 1992.

Lowi T. J. (1964). American Business, Public Policy, Case Studies, and Political Theory. World Politics, 6 (4), 677-715.

Manin, B. (1995). As Metamorfoses do Governo Representativo. Revista Brasileira de Ciências Sociais, 10 (29), 5-34.

Martins, M. L. R. (1997). Descentralização e Subprefeituras em São Paulo. Recuperado em 20 de maio, 2011, de: www.usp.br/fau/depprojeto/labhab/.../martinsdescentralizaerundina.pdf.

Mendes, M. (2001). Governabilidade no Município de São Paulo. Recuperado em 30 de junho, 2011, de http://www. Mollenkopf, J. H. (1992). The rise and fall of the Koch coalition in New York City politics. New Jersey: Princeton University Press.

Sanchéz, F. (2006). Mudar a cidade: o desafio do Orçamento Participativo. In R. Gaspar, M. Akerman \& R. Garibe (Orgs.). Espaço Urbano e Inclusão Social: a gestão pública na cidade de São Paulo (2001-2004) (pp. 49-56). São Paulo: Editora Fundação Perseu Abramo.

Santos, U. P. \& Barretta, D. (2004). As Subprefeituras em São Paulo. São Paulo: Hucitec: Prefeitura Municipal de São Paulo.

Sposati, A. (2001). A cidade em pedaços. São Paulo: Editora Brasiliense.

Sposati, A. (2002). Superando o discurso da descentralização municipal. In I. Calderón \& V. Chaia, V. (Orgs.). Gestão Municipal: descentralização e participação popular (pp. 73-80). São Paulo: Cortez.

Suplicy, M. (2002). Resgatando a dignidade da nossa cidade. In I. Calderón \& V. Chaia, V. (Orgs.). Gestão Municipal: descentralização e participação popular (pp. 113-122). São Paulo: Cortez.

Tatto, J. (2006). Governo Marta: eficiente e com prioridade. In R. Gaspar, M. Akerman \& R. Garibe (Orgs.). Espaço Urbano e Inclusão Social: a gestão pública na cidade de São Paulo (2001-2004) (pp. 291-304). São Paulo: Editora Fundação Perseu Abramo.

Thelen, K. \& Steinmo, S. (1992). Historical institutionalism in comparative In S. Steinmo, K. Thelen \& F. Longstreth (Orgs.). Structuring politics: historical institutionalism in comparative analysis (pp. 1-32). Cambridge: Cambridge University Press.

Weir, M. (1992). Ideas and politics of bounded innovation. In S. Steinmo, K. Thelen \& F. Longstreth (Orgs.). Structuring politics: historical institutionalism 
in comparative analysis (pp. 188-216). Cambridge: Cambridge University Press.

\section{Outras fontes}

Emenda n. 01 ao projeto de lei substitutivo n. 02 ao projeto de lei 001/2001 de autoria do vereador Carlos Neder (PT) que altera dispositivos e suprime artigos do projeto de lei n.01/01 (2004). Anais da Biblioteca da Câmara Municipal de São Paulo.

Lei Orgânica do Município de São Paulo (1990). Recuperado em 30 de setembro, 2011,

2011,

http://www.camara.sp.gov.br/images/stories/legislacao/Lei-Organica. Subprefeituras no município de São Paulo. Diário Oficial da Cidade. São Paulo: SP. Prefeitura Municipal de São Paulo.

Lei n. 13881, de 30 de julho de 2004 (2004). Dispõe sobre a criação, composição, atribuições e funcionamento do Conselho de Representantes e dá outras providências. Diário Oficial da Cidade. São Paulo: SP. Prefeitura Municipal de São Paulo.

Parecer substitutivo da Comissão de Política Urbana, Metropolitana e Meio Ambiente ao projeto de lei n. 001/01 que dispõe sobre a criação, composição, atribuições e funcionamento do Conselho de Representantes (2001). Anais da Biblioteca da Câmara Municipal de São Paulo.

\section{Entrevistas}

Aldaíza Sposati, Secretária Municipal de Assistência Social.

Félix Sanchez, Coordenador Municipal do Orçamento Participativo.

Genilson da Silva Santos, Chefe de Gabiente do Subprefeito da Freguesia do Ó.

Juan Aneros Fernandez, Assessor do Subprefeito da Capela do Socorro.

Márcia Barral, Subprefeita da Freguseia do Ó.

Tadeu Dias Pais, Subprefeito da Capela do Socorro.

Ubiratan dos Santos, Chefe de Gabinete da Secretaria de Governo Municipal.

Walter Alcântara, Subprefeito da Freguseia do Ó.

\section{ANEXO - ROTEIRO DE ENTREVISTA}

1. O que representava a descentralização e as subprefeituras? Quais eram as questões mais importantes envolvidas na 8. descentralização?
Parecer da Comissão de Constituição e Justiça sobre o projeto de lei $n$. 001/01 que dispõe sobre a criação, composição, atribuições e funcionamento do Conselho de Representantes (2001). Anais da Biblioteca da Câmara Municipal de São Paulo.

Projeto de lei 01-001/2001 (2001). Regulamenta, com fundamento no artigo 8ํ da Lei Orgânica do Município de São Paulo, a criação de Conselhos de Representantes no Município de São Paulo. Recuperado em 25 de agosto, 2011 ,

http://camaramunicipalsp.qaplaweb.com.br/iah/fulltext/projeto/PL0001-

2001.pdf.

Substitutivo de autoria do vereador José Laurindo (PT) ao projeto de lei $n$ 001/01 que dispõe sobre a criação, composição de atribuições do Conselho de Representantes (2001). Anais da Biblioteca da Câmara Municipal de São Paulo.

Substitutivo n. 02 de autoria dos líderes do PCdoB, PL, PDT, PSDB, PFL, $P S B, P T, P M D B, P R O N A, P P S, P T B$ e PP ao projeto de lei n. 001/01 que dispõe sobre a criação, composição, atribuições e funcionamento do Conselho de Representantes (2004). Anais da Biblioteca da Câmara Municipal de São Paulo.

2. Quais eram os atores sociais e políticos mais importantes em torno da política de descentralização nas regiões? Descreva quais os atores políticos (movimentos sociais, partidos, parlamentares etc.) atuantes e seus interesses? Quais os recursos políticos que esses atores dispunham? Esses atores incidiam na definição das políticas públicas definidas nas regiões? De que forma?

3. Como foi implantada desde o início a descentralização nas Subprefeituras? Descreva as principais etapas, problemas e avanços ocorridos.

4. Qual a sua opinião sobre o Conselho de Representantes. Por quê?

5. Como o Conselho de Representantes deveria se relacionar com as Subprefeituras e quais deveriam ser suas funções?

6. Quais foram as dificuldades, impasses e limites que ocorreram, de parte do governo municipal, para encaminhar o projeto dos Conselhos de Representantes?

7. Como os vereadores atuavam na sua Subprefeitura? 